\title{
DESIGN AND FINITE ELEMENT ANALYSIS OF NOVEL TWO-STAGE MAGNETIC PRECESSION GEAR
}

\author{
Macyszyn, L.; Jedryczka, C. \& Staniek, R. \\ Poznan University of Technology, pl. Marii Sklodowskiej-Curie 5, 60-965 Poznan, Poland \\ E-Mail: lukasz.macyszyn@ put.poznan.pl, cezary.jedryczka@put.poznan.pl, \\ roman.staniek@put.poznan.pl
}

\begin{abstract}
The paper presents a comparison of known magnetic gear constructions in terms of torque density and range of gear ratio. The theoretical bases, concept and the principle of operation of novel two-stage magnetic precession gear have been provided. The advantage of proposed gear is ability to obtain greater transmission ratios than currently known magnetic gears. Moreover, geometrical and kinematical relations between particular components of proposed gear were determined and the analyses of optimal gear ratio, which depends on the number of permanent magnets on the particular gear wheels, have been performed. For detailed analysis of the proposed gear performance the complex 3D FEM model of the precession transmission was created. Research was focused on determining distribution of magnetic flux density in air gaps as well as calculation of the torque waveforms acting on the output and input shafts as a function of the input shaft rotation angle. Selected results of the simulations showing proper operation of the proposed precession transmission system were presented and discussed.

(Received in June 2019, accepted in September 2019. This paper was with the authors 2 weeks for 2 revisions.)
\end{abstract}

Key Words: Magnetic Gear, Magnetic Flux, Transmitted Torque Analysis, Precession Gear

\section{INTRODUCTION}

Development of industrial engineering enforces inventing new machines of improved properties as durability, efficiency and stiffness. One of the key components of machine drive systems are gears, which are used to change the direction of a rotation, speed and torque. It is well known that the mechanical gears suffer from some inherent problems such as contact friction, tooth contact stress [1], noise, vibrations [2] and heat. In contrast, magnetic gears (MG) offer many advantages. The contactless transmission of torque by means of magnetic field provides physical isolation between the driver and the driven gear wheels [3,4]. As a result MG can be characterized by increased durability as well as reduction of vibration $[5,6]$ and noise level [7]. Magnetic gears provide also the "natural" protection against overload $[8,9]$. Despite discussed advantages, the magnetic gears have received relatively little attention mostly due to the poor torque density and relative complexity of the magnetic circuits [5]. Ranges of gear ratio and torque density for selected types of MG (as shown in Fig. 1) are summarized in Table I.

Table I: Comparison of exemplary magnetic gears $[3,6]$.

\begin{tabular}{|c|c|c|}
\hline Type of magnetic gear & $\begin{array}{c}\text { Torque density } \\
{\left[\mathrm{Nm}^{3} \mathrm{dm}^{3}\right]}\end{array}$ & Range of gear ratio \\
\hline Worm gear & $1-2$ & $1: 4-1: 80$ \\
\hline Bevel gear & $2-3$ & $1: 1-1: 5$ \\
\hline External spur gear & $10-20$ & $1: 1-1: 20$ \\
\hline Planetary gear & $45-110$ & $1: 3-1: 20$ \\
\hline $\begin{array}{c}\text { Coaxial gear with } \\
\text { ferromagnetic pole-pieces }\end{array}$ & $50-150$ & $1: 4-1: 10$ \\
\hline
\end{tabular}


a)

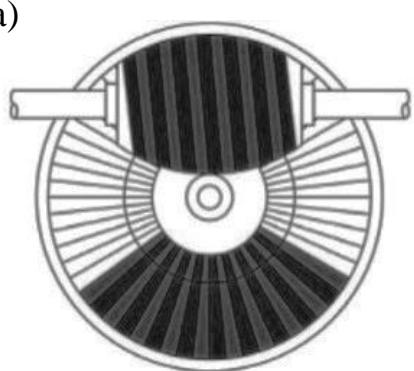

d)

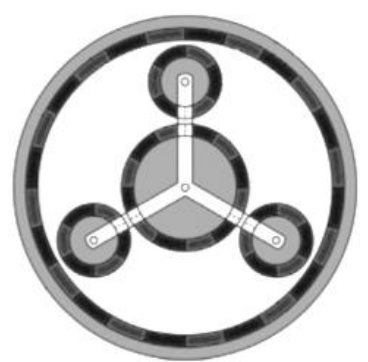

b)

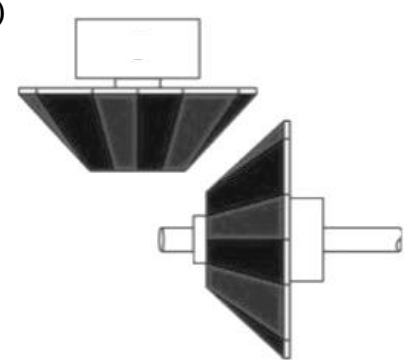

e)

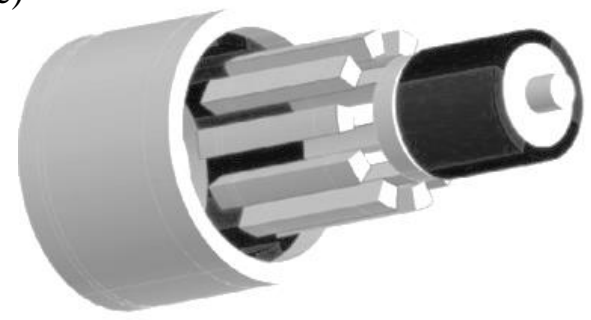

c)

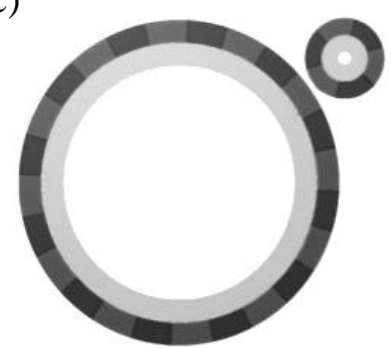

Figure 1: Magnetic gears: a) worm gear, b) bevel gear, c) spur gear, d) planetary gear, e) coaxial gear with ferromagnetic pole-pieces.

The idea of magnetic gear appeared in the beginning of the $20^{\text {th }}$ century. In 1901 C. G. Armstrong described electromagnetic spur gear in the US patent [10]. Early magnetic gear development was based only on its mechanical counterpart, mainly spur type and worm type gear technologies. However, the first noteworthy concept of a MG was introduced in the late 1960s by T. B. Martin in the US Patent [11]. It consists of three concentric parts: an inner magnet rotor, an outer magnet rotor and a flux modulator between them. Further study on this new MG topology was done by Laing and Ackermann [3]. Progress in developing highenergy product $\mathrm{NdFeB}$ permanent magnets and availability of advance methods and tools for analysis and design of complex magnetic circuits led to the focus on magnetic gears in many scientific teams over the world. The number of papers dedicated to magnetic gears has increased exponentially over the last two decades $[3,5]$. Currently, from the literature studies, the highest reported torque density has the improved topologies of the coaxial magnetic gear with ferromagnetic pole-pieces, proposed by Atallah and Howe in 2001 [4] (Fig. 1 e), in which all the permanent magnets simultaneously contribute to torque transmission. Despite high torque density, this design offers very low reduction ratio, though. Solution to this limit could be concept of two-stage magnetic precession gear, proposed in this paper.

\section{CONCEPT OF TWO-STAGE MAGNETIC PRECESSION GEAR}

The concept of two-stage magnetic precession gear is presented in Fig. 2. The intermediate ring is mounted with bearings to the input shaft at a specific precession angle $v$. This angle in mechanical precession gears is typically between $1.5^{\circ}$ and $5^{\circ}$ related to the main rotary axis of the gear [12]. In case of the magnetic precession gears, because of different principle of torque transmission, the precession angle can be greater than precession angle of typical mechanical precession gears. In the magnetic precession gear the permanent magnets are fixed on both sides of the intermediate ring. The intermediate ring performs the precession movement which is caused by the rotation of the input shaft and interaction of the magnetic field excited by the magnets fixed on the intermediate ring with the magnetic field excited by the magnets located on the immovable ring as well as with the magnetic field produced by the magnets fixed on the circumference of the output ring. 


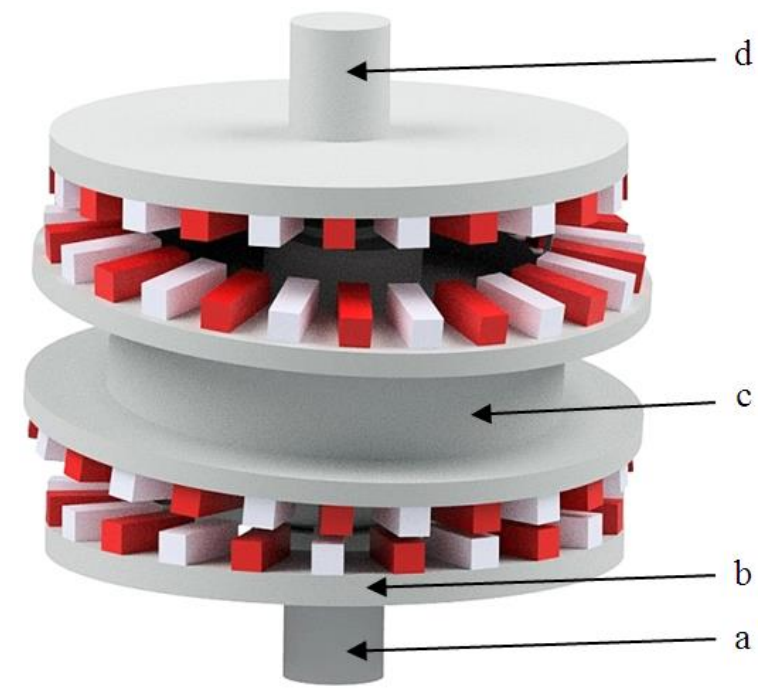

Figure 2: Concept of magnetic precession gear: $\mathrm{a}$ - input shaft, $\mathrm{b}$ - immovable ring, $\mathrm{c}$ - intermediate ring, $\mathrm{d}$ - output ring with output shaft

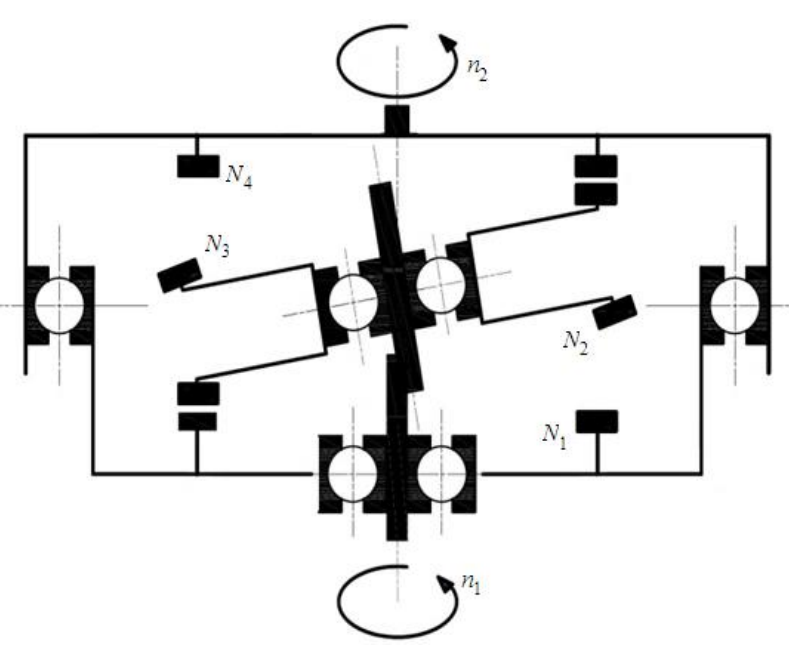

Figure 3: Kinematic scheme of the two-stage magnetic precession gear

The number of magnets on the particular rings influences on the transmission ratio (the kinematic scheme is shown in Fig. 3). The rotary speed of the output ring can be expressed by following relation [12]:

$$
n_{2}=n_{1} \cdot\left(1-\frac{N_{1}}{N_{2}} \cdot \frac{N_{3}}{N_{4}}\right)
$$

where $n_{1}$ is the input rotary speed, $n_{2}$ is the output rotary speed and $N_{i}$ is the number of magnetic poles on the $i^{\text {th }}$ ring, which is equal to the number of neodymium magnets on the ring.

The highest transmission ratio $i_{\max }=\frac{1}{N^{2}}$ is possible to obtain when:

$$
N_{1}=N-1 ; \quad N_{2}=N ; \quad N_{3}=N+1 ; \quad N_{4}=N
$$

This type of gear allows obtaining the transmission ratio in the range of $1 / 80$ to $1 / 10000$.

\section{GEOMETRICAL AND KINEMATICAL ANALYSIS OF TWO-STAGE MAGNETIC PRECESSION GEAR}

\subsection{Geometric analysis}

The symbols of geometrical dimensions of the two-stage precession gear are depicted in Fig. 4. The biggest impact on the dimensions of the magnetic precession gear have precession angle $v$ and transmission ratio (number of magnets on the circumferences of the rings $N_{1}-N_{4}$ ). The heights of gear components depend also on the predetermined radius $R$ of the gear.

$$
\begin{gathered}
h=h_{1}+h_{2}=\frac{R}{\operatorname{tg}(v)}\left(\frac{N_{3}}{N_{4}}+\frac{N_{2}}{N_{1}}-\frac{2}{\cos (v)}\right) \\
H_{1}=R \cdot \operatorname{tg}(v)+\frac{h_{1}}{\cos (v)}+d \\
H_{2}=R \cdot \operatorname{tg}(v)+\frac{h_{2}}{\cos (v)}+d \\
H=H_{1}+H_{2}=2 R \cdot \operatorname{tg}(v)+\frac{h}{\cos (v)}+2 d
\end{gathered}
$$




$$
r=\frac{h}{2} \cdot \operatorname{tg}(v)+\frac{R}{\cos (v)}
$$

where $d$ is width of the air gap, $R$ is radius of the gear, $H$ is height of the gear, $r$ is radius of the intermediate ring, $h$ is height of the intermediate ring.

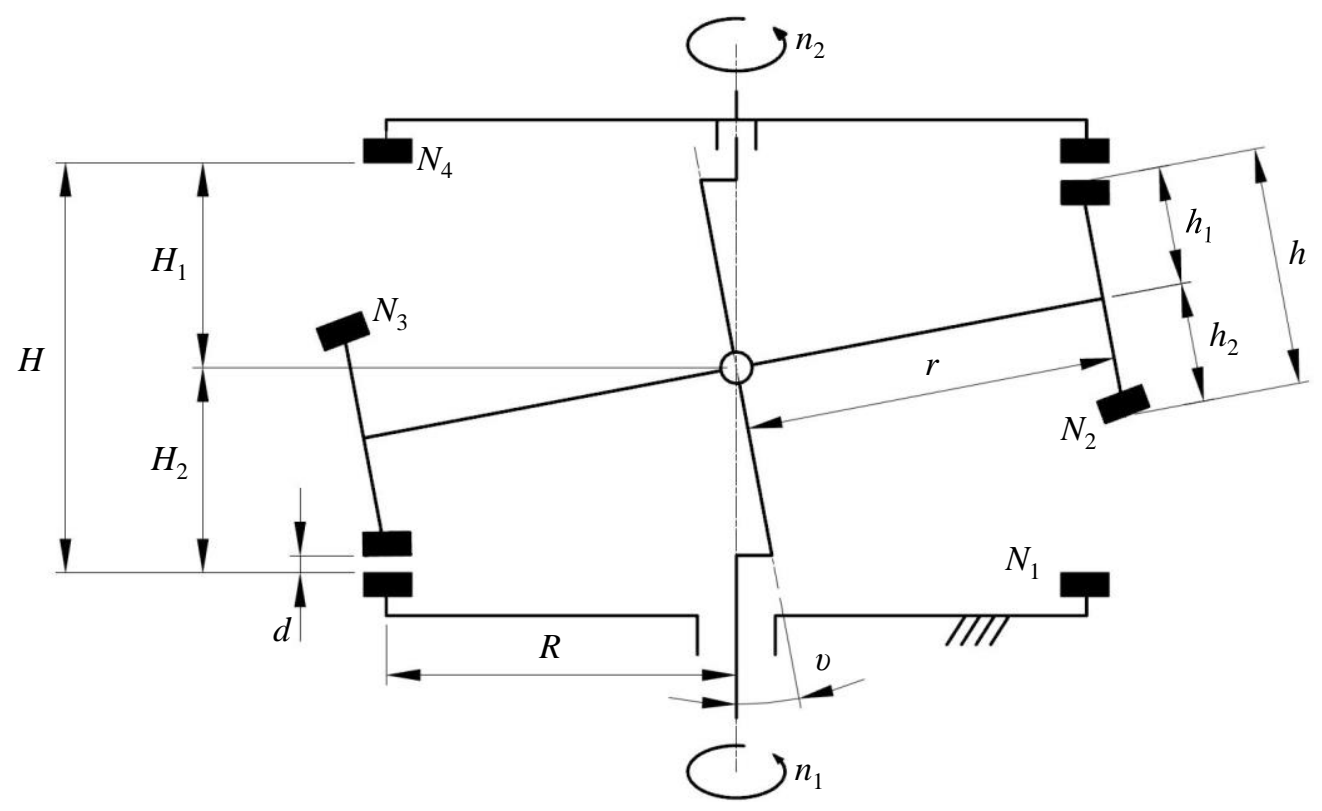

Figure 4: Geometrical scheme of the two-stage magnetic precession gear.

\subsection{Kinematic analysis}

The input shaft as well as output ring perform the rotational movement about the $\mathrm{Z}$ axis of the global fixed coordinate frame $S_{\mathrm{f}}$, which is the main rotary axis of the gear. The precession movement of intermediate ring is the combination of two motions. The first of them $\left(\omega_{i n}\right)$ is the rotation about the main rotary axis of the gear in $S_{\mathrm{f}}$ coordinate frame. The second motion, described by $\omega_{p}$, is the rotary motion about the $\mathrm{z}_{\mathrm{p}}$ axis of the intermediate ring fixed $\mathrm{S}_{\mathrm{p}}$ coordinate frame and is caused by the magnetic interaction with the permanent magnets located on the immovable ring [13]. Both of the discussed movements of the intermediate ring are shown in Fig. 5.
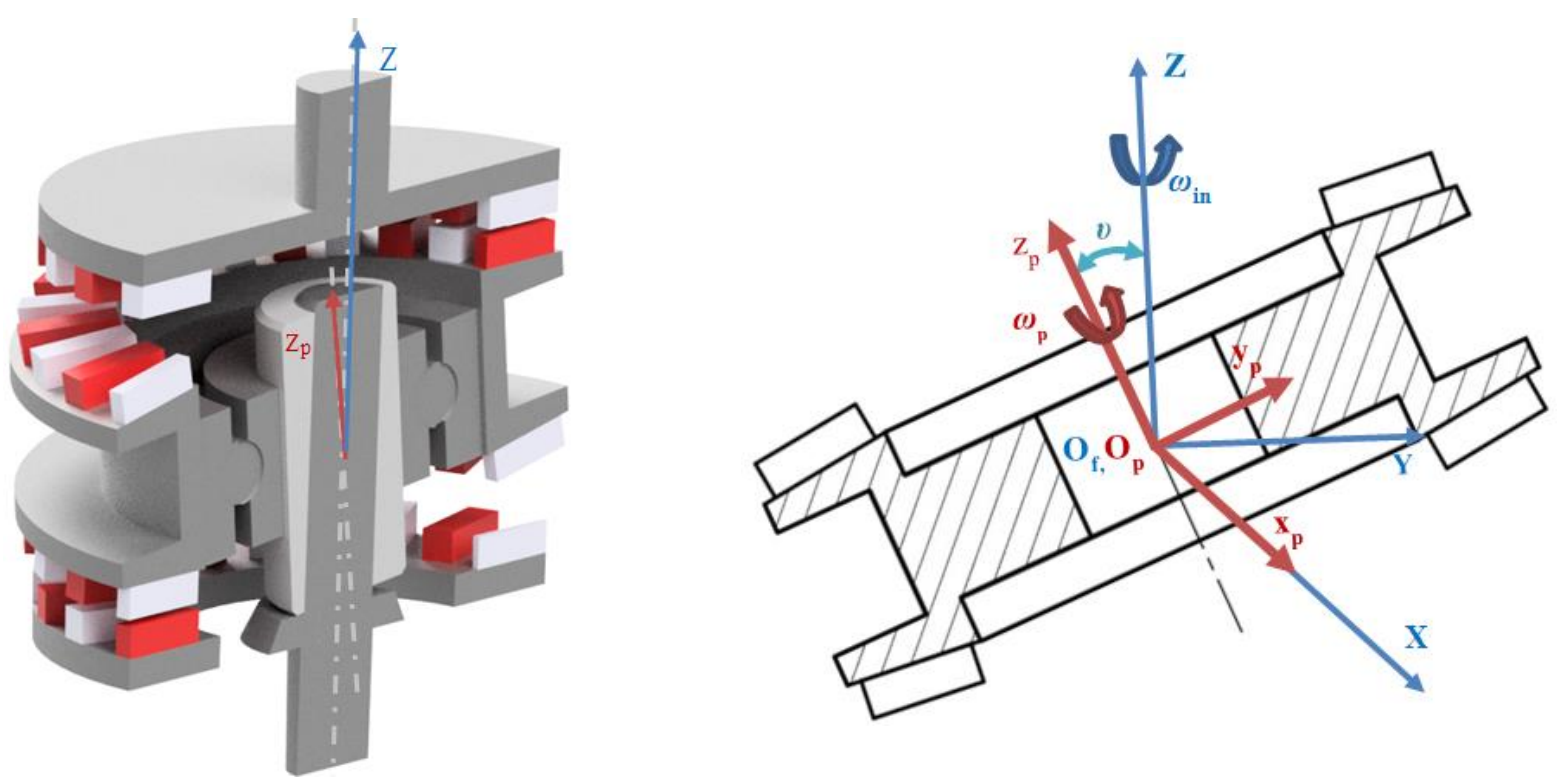

Figure 5: Intermediate ring rotations and coordinate relations. 
The rotational movement of the intermediate ring can be expressed by following formula [13]:

$$
\boldsymbol{\Omega}=\omega_{\text {in }} \cdot \widehat{\mathrm{K}}+\omega_{p} \cdot \widehat{\mathrm{k}}
$$

where $\boldsymbol{\Omega}$ is the angular velocity of intermediate ring, $\omega_{\text {in }}$ is theangular speed of the input shaft around the $\mathrm{Z}$ axis of $\mathrm{S}_{\mathrm{f}}$ frame, $\omega_{p}$ is the angular speed of the intermediate ring around its own axis, $\hat{\mathrm{k}}$ is the unit vector in $z_{p}$ direction of $S_{p}$ frame, $\widehat{\mathrm{K}}$ is the unit vector in $\mathrm{Z}$ direction of $\mathrm{S}_{\mathrm{f}}$ frame.

The following equation describes the angular speed of the intermediate ring about the $z_{p}$ axis:

$$
\omega_{p}=\left(-\omega_{i n}\right) \cdot\left(\frac{N_{1}}{N_{2}}\right)
$$

Transforming $\omega_{\text {in }} \cdot \widehat{\mathrm{K}}$ from $\mathrm{S}_{\mathrm{f}}$ to the $\mathrm{S}_{\mathrm{p}}$ frame allows expressing the total angular velocity of the intermediate ring in $S_{p}$ coordinate frame:

$$
\boldsymbol{\Omega}=\left\{\begin{array}{lll}
0 & -\omega_{\text {in }} \sin (v) & \omega_{\text {in }}\left(\cos (v)-\frac{N_{1}}{N_{2}}\right)
\end{array}\right\}
$$

\section{FINITE ELEMENT ANALYSIS OF TWO-STAGE MAGNETIC PRECESSION GEAR PERFORMANCE}

Transmitted torque is one of major functional parameters of a magnetic gear mechanism. Therefore, this is an essential task to complete design of magnetic gear is to develop precise mathematical model allowing to determine transmitted torque value. In general, the torque of MG can be calculated on the basis of magnetic field distribution inside the air gaps between movable elements of the MG.

There are various techniques to determine the magnetic field distribution in magnetic transducers. In general, the two main approaches can be distinguished including analytical and numerical methods [14-18]. The analytical methods are based on simplified mathematical description of system components forming so called magnetic equivalent circuits (MEC). Such circuit models, especially when their lumped parameters are verified or identified by means of experiment or measurements of existing device are very useful in system level analysis, like performance studies on different load conditions, etc. [19]. Usually, the complexity and number of equations needed to be solved is not high, making such approaches computationally effective. For determining the magnetic field distribution and calculating the transmitted torque of MG the analytical technique based on current sheet model (CSM) of permanent magnet is often proposed [14, 15]. Application of MEC and CSM allows for determination of the magnetic flux density within the air gap between movable elements of the MG. The magnetomotive force (MMF) of each permanent magnet is replaced by a series of infinitesimal current sheets situated along the magnet height. Despite short computation time, suitability of this method for MG design purposes is rather limited due to high number of assumptions needed to be taken and complexity of model formulation. Limited usefulness of analytical methods for MG design purposes is especially apparent for MG of sophisticated geometries and kinematics. Therefore for determining the magnetic field distribution in the proposed precession magnetic gear the Finite Element Method (FEM) has been applied. The classical formulation of magnetostatic 3D problem has been employed. The magnetostatic field solution verifies the following two Maxwell's equations:

$$
\begin{aligned}
\nabla \times \boldsymbol{H} & =\boldsymbol{j} \\
\nabla \cdot \boldsymbol{B} & =0
\end{aligned}
$$


with respect to the constitutive (material) relationship:

$$
\boldsymbol{B}=\mu_{0} \mu_{r} \boldsymbol{H}+\mu_{0} \boldsymbol{M}_{\mathrm{p}}
$$

where $\boldsymbol{H}$ is the magnetic field strength vector, $\boldsymbol{j}$ is the conduction current density vector, $\boldsymbol{B}$ is the magnetic flux density vector, $\boldsymbol{M}_{p}$ is the permanent magnet magnetization vector, $\mu_{0}$ is magnetic permeability of the vacuum, $\mu_{r}$ is relative magnetic permeability of the medium.

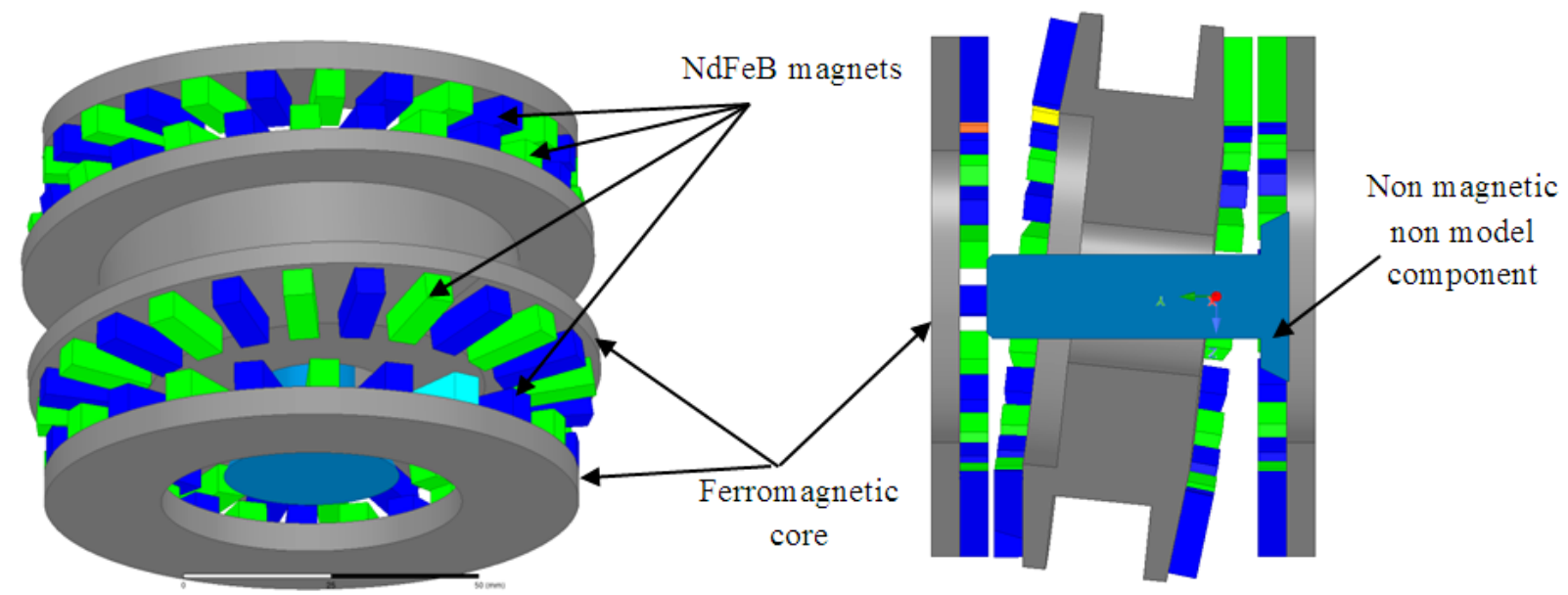

Figure 6: Geometry of developed 3D FEM model.

The detailed analysis of proposed precession magnetic gear have been carried out by employing numerical field model developed in professional FEM package, Ansys Maxwell 3D. In the employed package to formulate the matrix equations of FEM the magnetic scalar potential is used. To handle with the nonlinearity of the ferromagnetic materials the classic Newton-Raphson iterative algorithm with user-controlled accuracy is applied.

The geometry of the developed model has been shown in Fig. 6. The geometry consist of 96 rectangular $\mathrm{NdFeB}$ magnets of $\mathrm{N} 33$ grade fixed on three ferromagnetic yokes made of steel 1010 type. The gear ratio equals 1/144. Permanent magnet properties as well as $\mathrm{BH}$ curve of applied ferromagnetic material have been shown in Fig. $7 \mathrm{~b}$ and 7 a respectively.

a) $\mathbf{B}[\mathbf{T}]$

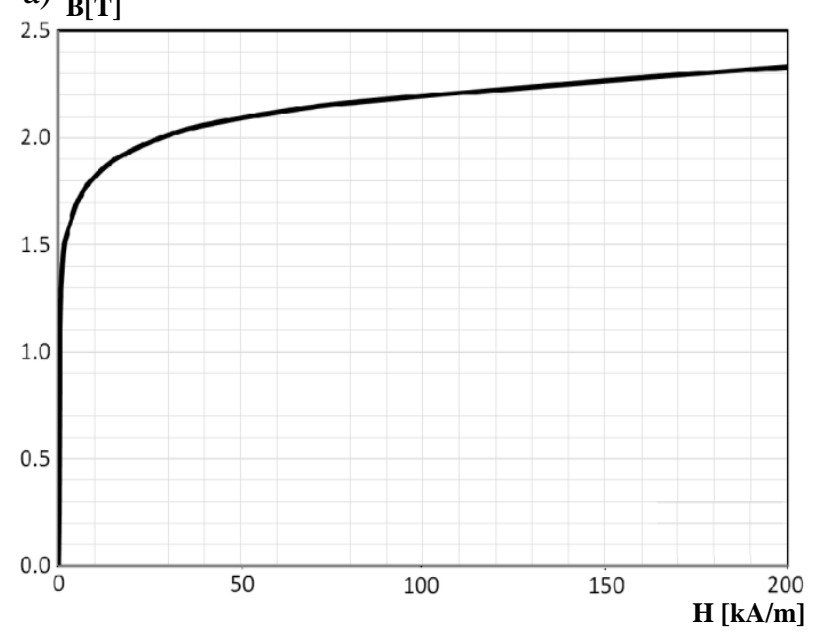

b)

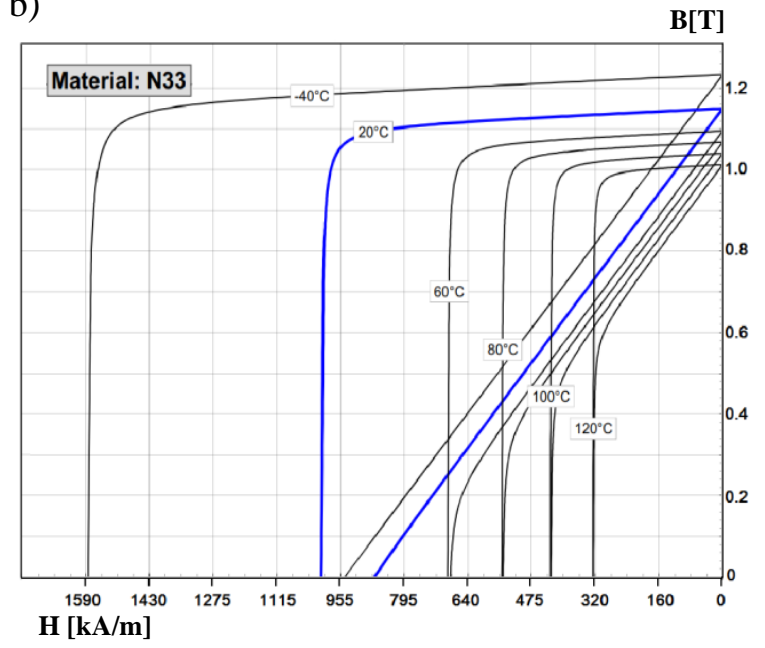

Figure 7: B-H curve of: a) applied ferromagnetic core material, b) N33 grade NdFeB magnet [20].

The considered system consists of two air gaps involved for torque transmission. Due to different rotation axis the torque calculation have been performed on three geometries as illustrated in Fig. 8. 
a)

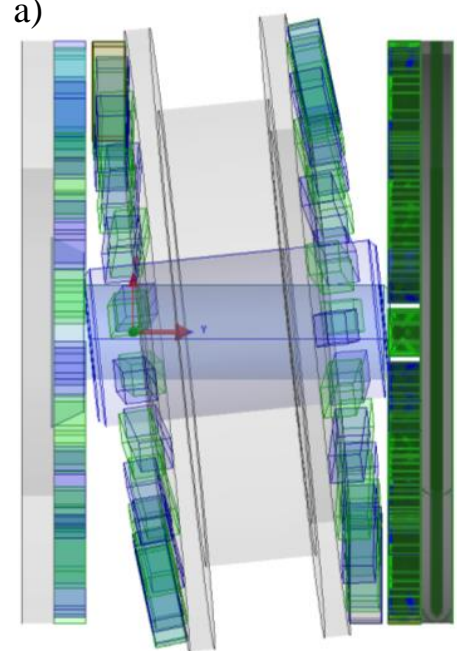

b)

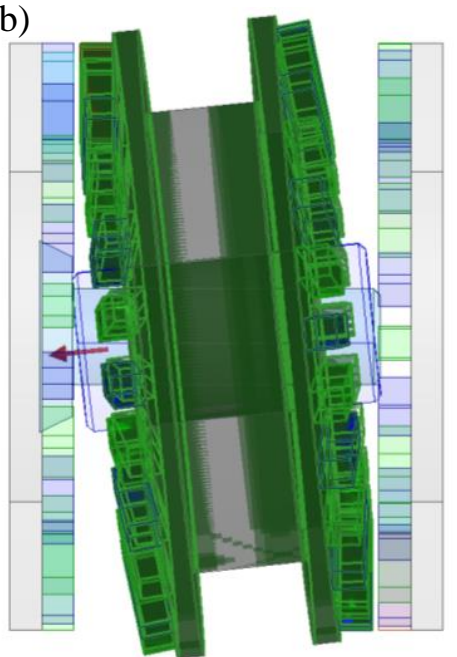

c)

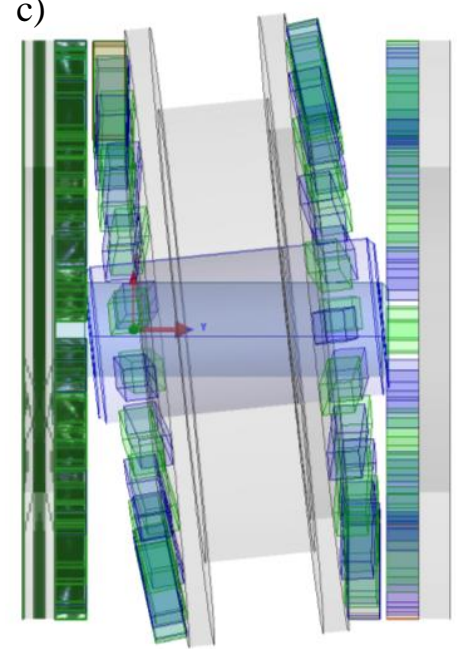

Figure 8: Geometry assignment for torque calculation: a) output ring, b) input shaft and intermediate ring, c) base plate - fixed.

The considered domain has been subdivided into about 897000 tetrahedral elements. Applied 3D FE mesh has been shown in Fig. 9. To increase readability, the mesh of the air region has not been plotted.
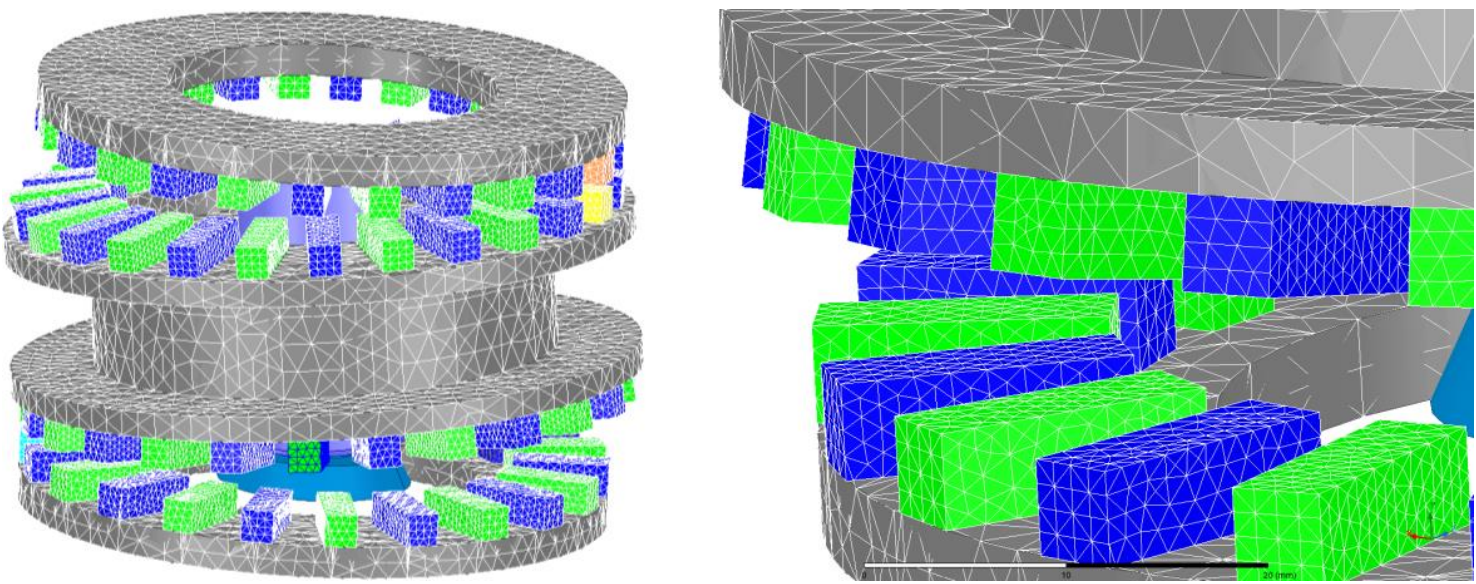

Figure 9: Applied 3D FE mesh.

One of the weak points of MG when comparing to traditional gears is low mechanical stiffness [5]. It can be easily explained by understating the similarities of MG torque transmission to operation of traditional synchronous machines. For example, focusing on the output ring torque (see geometry assignment shown in Fig. 8) and neglecting the base plate torque it can be seen that the output torque value will depend on angle between intermediate ring magnets and output shaft magnets. Of course this relation is bidirectional, which means that the angle between input and output shafts will depend on the load torque value as well. This angle can be interpreted as an internal load angle in synchronous machines. Taking the number of magnets on each disc as a pole number and neglecting the reluctance torque the relation between torque and load angle will be close to sinusoidal. Such torque versus angle dependencies will occur between all movable parts of the studied MG and renders the simulation of magnetic field inside studied MG more complex. In general case the angular positions of input shaft and output shafts as well as base plate should be determined solving the mechanical equilibrium equations for given value of input shaft speed and load torque value. Implementation of such approach together with calculation of magnetic field distribution in complex 3D system by means of FEM will lead to not acceptable from 
practical point of view computation time. In presented studies the simplified and effective approach has been proposed in which the MG torque is determined by means of FEA for different positions of the input shaft assuming that the proposed gear kinematic will be as derived theoretically, see Eqs. (8) to (10), and the load angle will be equal to about electrical 80 degrees.
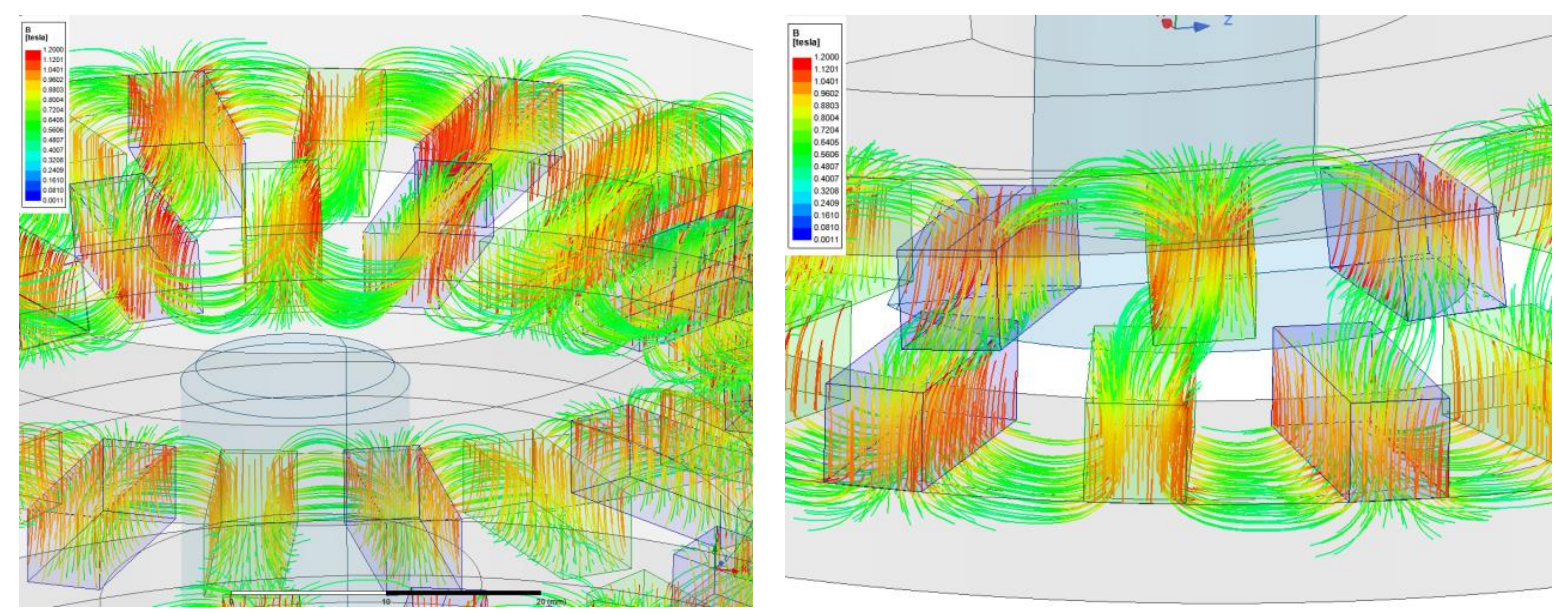

Figure 10: Distribution of magnetic field lines for chosen values of driving shaft angular position.

The exemplary magnetic flux distributions for selected values of driving input shaft position have been shown in Fig. 10, while determined magnetic flux density distributions (z component) along the circumference of the air gap between intermediate and output rings for two values of output shaft angular position has been shown in Fig. $11 \mathrm{a}$. It can be noted that magnetic flux density is on acceptable level not causing the saturation of the ferromagnetic yokes. Calculated input and output shaft torque waveforms have been shown in Fig. $11 \mathrm{~b}$. It can be observed that average values (against input shaft angle) of both input and output shaft torques are non-zero. That proves correctness of developed model and derived theoretical analyses on proposed gear kinematics. Nevertheless, the slight torque fluctuations can be observed - it is known issue in magnetic gears.

a)

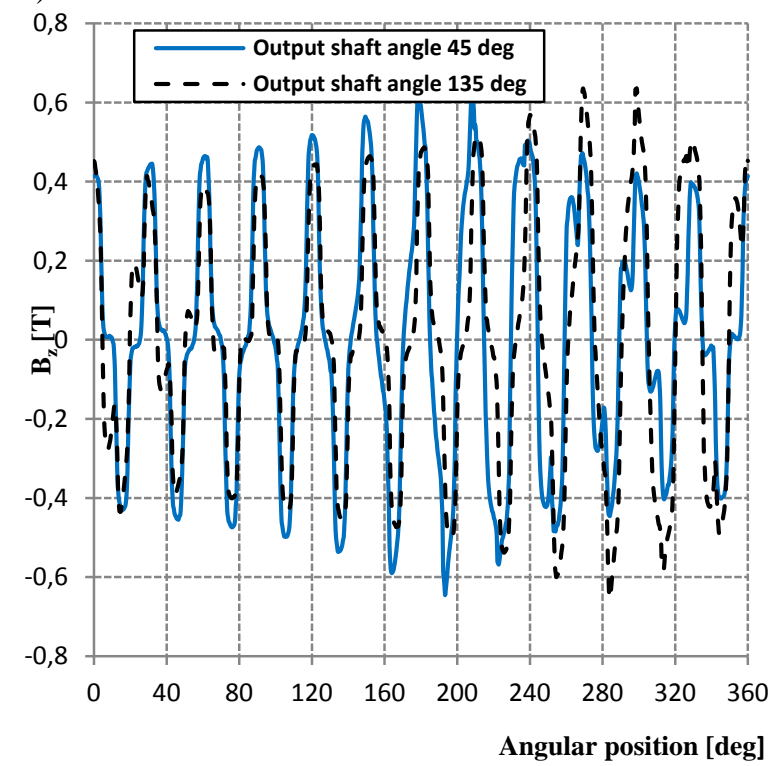

b)

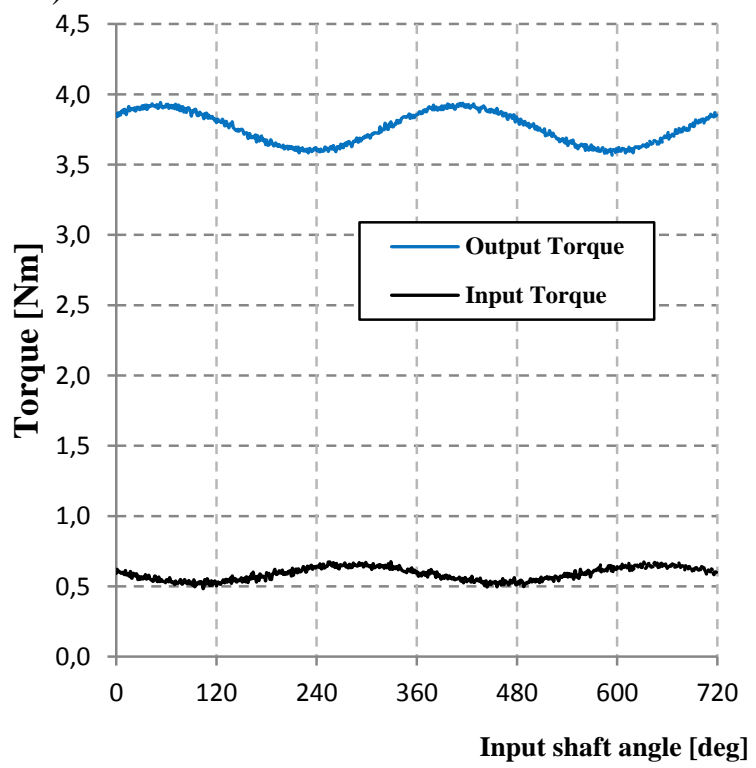

Figure 11: Magnetic flux density distribution (z component) along the circumference of the air gap between intermediate and output rings for two values of output shaft angular position (a); and calculated input and output torque waveforms (b). 


\section{CONCLUSION}

Proposed novel design of two-stage precession magnetic gear cannot compete with their improved topologies of the coaxial magnetic gears with ferromagnetic pole-pieces, proposed by Atallah and Howe in 2001, in terms of transmitted torque density. However, its range of transmission ratio is hard to reach by any other currently known magnetic gear. Geometric and kinematic analysis allowed creating FEM model of the gear. Studying determined torque waveforms, it was observed that average values (against input shaft angle) of both input and output shaft torques are non-zero. It proves correctness of developed model and derived theoretical analyses on proposed gear kinematics. Nevertheless, the slight input and output torque fluctuations can be observed - it is known issue in magnetic gears and mitigation of this problem is the scope of design optimization calculations not reported in here.

On the base of FEM model results, experimental work will be made. A prototype will be built and investigated, which will enable to validate the model as well as check the efficiency.

\section{ACKNOWLEDGEMENT}

The current research is supported by The Ministry of Science and Higher Education (Poland), projects 02/22/SBAD/1501 and 04/42/DSPB/0472.

\section{REFERENCES}

[1] Zeng, Q. L.; Wang, K.; Wan, L. R. (2018). Modelling of straight bevel gear transmission and simulation of its meshing performance, International Journal of Simulation Modelling, Vol. 17, No. 3, 521-533, doi:10.2507/IJSIMM17(3)CO12

[2] Ramadani, R.; Belsak, A.; Kegl, M.; Predan, J.; Pehan, S. (2018). Topology optimization based design of lightweight and low vibration gear bodies, International Journal of Simulation Modelling, Vol. 17, No. 1, 92-104, doi:10.2507/IJSIMM17(1)419

[3] Miladinovic, S.; Ivanovic, L.; Blagojevic, M.; Stojanovic, B. (2017). The development of magnetic gears for transportation applications, International Journal for Vehicle Mechanics, Engines and Transportation Systems, Vol. 43, No. 1, 41-55, doi:10.24874/mvm.2017.43.01.04

[4] Atallah, K.; Howe, D. (2001). A novel high-performance magnetic gear, IEEE Transactions on Magnetics, Vol. 37, No. 4, 2844-2846, doi:10.1109/20.951324

[5] Tlali, P. M.; Wang, R.-J.; Gerber, S. (2014). Magnetic gear technologies: A review, International Conference on Electrical Machines (ICEM), 544-550, doi:10.1109/ICELMACH.2014.6960233

[6] Li, X.; Chau, K.-T.; Cheng, M.; Hua, W. (2013). Comparison of magnetic-geared permanentmagnet machines, Progress in Electromagnetics Research, No. 133, 177-198, doi:10.2528/ PIER12080808

[7] Macyszyn, L.; Pabiszczak, S. (2016). Frictionless gears as an alternative for the traditional gears, Mechanik, Vol. 2016, No. 12, 1770-1773, doi:10.17814/mechanik.2016.12.562

[8] Kowol, M.; Kolodziej, J.; Lukaniszyn, M. (2014). Performance analysis of the magnetic gear, Maszyny Elektryczne - Zeszyty Problemowe, Vol. 2014, No. 4, 125-130

[9] Mezyk, A.; Tomas, A. (2013). Magnetic gears - the new quality in torque transmission, Przeglad mechaniczny, Vol. 2013, No. 10, 40-44

[10] Armstrong, C. G. (1901). Power transmitting device, US Patent 687292, United States Patent Office

[11] Martin Jr., T. B. (1968). Magnetic transmission, US Patent 3378710, United States Patent Office

[12] Macyszyn, L.; Myszkowski, A.; Staniek, R.; Pabiszczak, S. (2017). Two-stage precession type gear: design, geometric and kinematic analysis, Proceedings of the ASME 2017 International Mechanical Engineering Congress and Exposition, Paper IMECE2017-70525, V014T07A014, 6 pages, doi:10.1115/IMECE2017-70525

[13] Saribay, Z. B.; Bill, R. C. (2013). Design analysis of pericyclic mechanical transmission system, Mechanism and Machine Theory, Vol. 61, 102-122, doi:10.1016/j.mechmachtheory.2012.10.007 
[14] Wu, Y.-C.; Wang, C.-W. (2015). Transmitted torque analysis of a magnetic gear mechanism with rectangular magnets, Applied Mathematics \& Information Sciences, Vol. 9, No. 2, 1059-1065, doi:10.12785/amis/090257

[15] Boules, N. (1984). Two-dimensional field analysis of cylindrical machines with permanent magnet excitation, IEEE Transactions on Industry Applications, Vol. IA-20, No. 5, 1267-1277, doi:10.1109/TIA.1984.4504593

[16] Huang, S. M.; Sung, C. K. (2002). Analytical analysis of magnetic couplings with parallelepiped magnets, Journal of Magnetism and Magnetic Materials, Vol. 239, No. 1-3, 614-616, doi:10.1016/S0304-8853(01)00683-7

[17] Huang, J.; Wang, D.; Zhang, D. (2012). The torque characteristic analysis and simulation on electromagnetic gears, Energy Procedia, Vol. 17, Part B, 1274-1280, doi:10.1016/ j.egypro.2012.02.238

[18] Knypinski, L.; Nowak, L.; Jedryczka, C. (2015). Optimization of the rotor geometry of the linestart permanent magnet synchronous motor by the use of particle swarm optimization, COMPEL - The International Journal for Computation and Mathematics in Electrical and Electronic Engineering, Vol. 34, No. 3, 882-892, doi:10.1108/COMPEL-10-2014-0276

[19] Derbas, H. W.; Williams, J. M.; Koenig, A. C.; Pekarek, S. D. (2009). A comparison of nodaland mesh-based magnetic equivalent circuit models, IEEE Transactions on Energy Conversion, Vol. 24, No. 2, 388-396, doi:10.1109/TEC.2008.2002037

[20] ARNOLD Magnetic Technologies. Technical Publications, Neodymium Iron Boron Product Catalog, from https://www.arnoldmagnetics.com/resources/technical-publications/\#productdata-sheets, accessed on 16-04-2019 